\title{
Psychometric Properties of Three Instruments to Measure
} Fatigue With Myocardial Infarction

\author{
Anne M. Fink ${ }^{1}$, Ann L. Eckhardt ${ }^{1}$, Michelle M. Fennessy ${ }^{1}$, Jessica Jones ${ }^{2}$, Donna Kruse ${ }^{3}$, \\ Kathryn J. VanderZwan ${ }^{1}$, Catherine J. Ryan ${ }^{1}$, and Julie J. Zerwic ${ }^{1}$ \\ ${ }^{1}$ University of Illinois at Chicago \\ ${ }^{2}$ Central DuPage Hospital, Winfield, Illinois \\ ${ }^{3}$ Sherman Hospital, Elgin, Illinois
}

\begin{abstract}
The purpose of this study was to evaluate the psychometric properties of three questionnaires to measure fatigue with myocardial infarction. The Fatigue Symptom Inventory Interference Scale, Profile of Moods States Fatigue subscale (POMS-F), and Short Form 36 (SF-36) Vitality Scale were completed during hospitalization $(n=116)$ and 30 days after hospital admission $(n=49)$. Moderate to strong correlations were found among each of these fatigue scales and between each fatigue scale and measures of other variables to include vigor, depressed mood, anxiety, and physical functioning. POMS-F scores decreased significantly at Time 2, but this decline in fatigue was not validated on the other fatigue scales. Patients' Time 1 scores reflected significantly more fatigue compared to published scores for healthy adults. The ability to discriminate between groups suggests that the instruments may be useful for identifying patients with cardiovascular risk factors who report clinically significant fatigue.
\end{abstract}

\section{Keywords}

cardiovascular; fatigue; descriptive quantitative; acute care

Myocardial infarction (MI) is associated with significant morbidity and mortality, and early recognition of MI symptoms by both patients and clinicians is critical for ensuring prompt medical interventions. Experts estimate that in 2009 in the United States alone, 610,000 and 325,000 people will have a new MI or a recurrent MI, respectively (Lloyd-Jones et al., 2009). Many people expect to have severe chest pain or shortness of breath with MI, and they are less likely to seek treatment when they do not have the symptoms they expect (Johnson \& King, 1995). Severe fatigue may be a symptom of MI in some patients (Appels \& Mulder, 1988; DeVon, Ryan, \& Zerwic, 2004; McSweeney et al., 2003; Schuitemaker, Dinant, \& Appels, 2004; Shin, Martin, \& Howren, 2009; Ryan et al., 2007), and fatigue may occur before or in the absence of commonly recognized MI symptoms (McSweeney et al., 2003; Ryan, DeVon, \& Zerwic, 2005). Considering these findings, research about fatigue with MI is important so that patients and clinicians may recognize the characteristics of MIrelated fatigue. To achieve this aim, however, reliable and valid instruments must be identified for measuring fatigue in this population. Fatigue is challenging to measure, and to

Corresponding Author: Anne M. Fink, Department of Biobehavioral Health Science, University of Illinois at Chicago, 845 S. Damen Ave., Room 717 (MC 802), Chicago, IL 60612-7350, afink2@uic.edu.

Declaration of Conflicting Interests

The authors declared no conflicts of interest with respect to the authorship and/or publication of this article. 
date, no fatigue instrument has been established as a gold standard for a cardiac population. In addition, it is not known whether established fatigue questionnaires are sensitive to changes that occur in fatigue before and after MI. The purpose of this study was to measure fatigue before and after MI and to examine the psychometric properties of the Fatigue Symptom Inventory (FSI) Interference Scale, Profile of Mood States Fatigue subscale (POMS-F), and Short Form 36 (SF-36) Vitality Scale.

\section{Fatigue With Myocardial Infarction}

Fatigue is defined as a complex and subjective state involving an extreme lack of energy, which is not simply the result of physical exertion or a lack of sleep (Aaronson et al., 1999; Friedman \& Stephens, 2008; Ream \& Richardson, 1996). In 1974, Nixon and Bethell described fatigue as a "precoronary symptom." In later investigations, others identified fatigue as a prodromal MI symptom that may be particularly important in women. In a qualitative study of women's MI symptoms, McSweeney and Crane (2000) found that women reported overwhelming fatigue as their most common prodromal symptom, with the duration of fatigue ranging from a few weeks to 2 years before MI. In interviews with 215 patients (44\% women) 3 to 14 days after hospitalization for MI, DeVon et al. (2004) found that fatigue was the second most commonly experienced symptom before MI (second to chest pain) and was reported by $65 \%$ of the sample. The duration and severity of patients' fatigue, however, was not reported.

Others have examined the relationships between cardiovascular risk factors and vital exhaustion, which is defined as a state of unusual fatigue, increased irritability, and demoralization (Appels \& Mulder, 1988; Schuitemaker et al., 2004). In a 5-year cohort study in the Netherlands, investigators examined the relationship between vital exhaustion (measured using the Maastricht Questionnaire) and future coronary events. In a sample of 3,877 men from this cohort, vital exhaustion was found to predict future MI when controlling for age, hypertension, smoking, and cholesterol (Appels \& Mulder, 1988). In a subsequent analysis of 2,433 individuals from this cohort (50\% women), the presence of vital exhaustion tripled the risk of future MI when controlling for age, gender, systolic blood pressure, total cholesterol, smoking habits, self-reported cardiovascular disease, and diabetes mellitus (Schuitemaker et al., 2004). The above findings suggest that the measurement of fatigue and vital exhaustion may be useful for identifying patients at increased risk of acute coronary events.

In addition to being a symptom noted before MI, fatigue has also been reported as a burdensome symptom following MI. Alsén, Brink, and Persson (2008) interviewed patients $(N=19,37 \%$ women) 4 months after MI and found that those who scored $\geq 15$ (20 points possible) on at least one subscale of the Multidimensional Fatigue Inventory described that severe fatigue interfered with activities of daily living, cognitive functioning, and social interactions. Consistent with this finding, Varvaro, Sereika, Zullo, and Robertson (1996) found that many women reported chronic fatigue 6 weeks after MI. These findings highlight the presence of persistent fatigue after MI but are limited by the lack of measures to quantify post-MI fatigue severity and duration.

Before investigators can further examine fatigue with MI, they must identify appropriate instruments for measuring fatigue in this population. Fatigue is challenging to measure because fatigue is subjective (requiring self-report) and multidimensional. Piper, Lindsey, and Dodd (1987) defined fatigue as a multidimensional symptom because fatigue involves physiological, behavioral, and cognitive factors. In the setting of MI, there may be dynamic variability in the quality, severity, and timing of fatigue, which may contribute to poor testretest reliability. There are many instruments designed to measure fatigue; however, only a 
small number of instruments have demonstrated good psychometric properties or responsiveness to changes in fatigue over time (Whitehead, 2009). In addition, fatigue and depressive symptoms are highly correlated (Irvine et al., 1999); therefore, it is important to control for depression or depressed mood in studies about fatigue. Other variables, such as sleep and anemia, are important in fatigue research as well, but their influence on fatigue questionnaire scores has not been fully investigated in populations with cardiovascular disease.

In summary, there is evidence that fatigue is a common and early symptom before MI; however, knowledge about the course of fatigue before and after MI is limited by the lack of information about psychometrically sound instruments for measuring fatigue in this population.

\section{Purpose}

The purpose of this study was to determine the psychometric properties of the FSI Interference Scale, POMS-F, and SF-36 Vitality Scale in measuring fatigue in men and women with MI at two time points. Time 1 questionnaires were administered during hospitalization, and these scores reflect symptoms in the week preceding hospitalization for MI. Time 2 questionnaires were mailed to participants, and these scores reflect the period of 30 days after hospital admission. We selected the 30 -day time period to detect clinically significant changes in fatigue. Theoretically, this time period allowed for patients to adjust to the medications started during hospitalization, in addition to avoiding the confounding influence of aggressive secondary prevention behaviors such as exercise (e.g., cardiac rehabilitation). Cardiac rehabilitation is typically started after follow-up with a cardiologist and approximately 4 weeks after hospital discharge.

We tested the following hypotheses to determine the psychometric properties of the FSI Interference Scale, POMS-F, and SF-36 Vitality Scale:

\section{Hypothesis 1 (Convergent Validity)}

At Time 1, we expected to find a moderate or stronger positive correlation $(r>+.50)$ between scores on the FSI Interference Scale and the POMS-F because both scales were designed to measure aspects of fatigue. We expected to find moderate or stronger inverse correlations $(r>-.50)$ between the FSI Interference Scale and the SF-36 Vitality Scale and between the POMS-F and the SF-36 Vitality Scale.

\section{Hypothesis 2 (Discriminant Validity-Correlation Matrix)}

At Time 1, we expected to find weak correlations $(r \leq .30)$ between the measures of fatigue and measures reflecting other moods or symptoms (i.e., anxiety, anger [measured using the POMS], physical functioning, and pain [measured using the SF-36]). Although fatigue is a multidimensional symptom, fatigue is not a defining attribute of anxiety or anger. Physical inactivity, pain, and negative mood states may have a relationship with fatigue, but these variables are conceptually different from fatigue. Our purpose was to identify robust fatigue measures, so we expected to find weak correlations between fatigue and measures of these variables.

\section{Hypothesis 3 (Discriminant Validity-Healthy Group Comparison)}

In comparison to published scores for healthy adults, patients' Time 1 scores were expected to be significantly higher on the FSI Interference Scale and POMS-F and significantly lower on the SF-36 Vitality Scale. 


\section{Hypothesis 4 (Construct Validity)}

We hypothesized that patients would report significantly higher scores on the FSI Interference Scale and POMS-F and lower scores on the SF-36 Vitality Scale for Time 1 compared to Time 2 . This hypothesis was based on evidence that fatigue may be a prodromal or early warning symptom of MI (Appels \& Mulder, 1988; DeVon et al., 2004; McSweeney \& Crane, 2000).

\section{Method}

\section{Subjects and Procedures}

One hundred sixteen subjects hospitalized for MI were recruited from six Midwestern hospitals. MI was confirmed by troponin I $>0.05 \mathrm{ng} / \mathrm{mL}$. Patients had stable hemodynamic parameters (blood pressure $>90 / 60$ and $<180 / 100 \mathrm{mmHg}$, heart rate $50-100$ beats per minute) and the absence of pain at the time of study enrollment. Subjects were able to read English and were alert and oriented to person, place, and time. An Institutional Review Board at each site approved the study, and all subjects provided informed consent. The researchers reviewed the patients' medical records to document medical history, medications taken prior to admission and during hospitalization, infarct type and location, and current laboratory and diagnostic test results. Patients completed the FSI, POMS, and SF-36 at Time $1(n=116)$ and Time 2 (30 days after hospital admission, $n=49,42 \%$ response rate).

\section{Instruments}

The FSI, POMS, and SF-36 were selected for this study because others have reported strong psychometric properties for these measures. In addition, these instruments allow for the measurement of other variables (e.g., depressed mood, vigor, anxiety, physical functioning), which are important for psycho-metric testing of the fatigue measures. The FSI Interference Scale and POMS-F measure fatigue directly, and the SF-36 Vitality Scale is often used as a proxy measure of fatigue (Dickens et al., 2006; Meeske, Siegel, Globe, Mack, \& Bernstein, 2005).

\section{FSI Interference Scale}

The FSI was developed by Hann and colleagues (1998) to measure fatigue in patients with cancer and includes 13 quantitative questions and one qualitative question. The 13 quantitative questions are each answered using a 10-point Likert-type scale. We used the seven-item Interference Scale (FSI Interference Scale), which consists of Questions 5 to 11, to measure the degree to which fatigue interfered with the patients' daily activities in the past week. The FSI Interference Scale total score is summed and then divided by the number of items (7), yielding scores ranging from 0 to 10 . Higher scores reflect more interference as a result of fatigue. FSI Interference Scale scores of 3 or greater on any of the items indicate clinically significant fatigue (Donovan, Jacobsen, Small, Munster, \& Andrykowski, 2008). Excellent internal consistency reliability ( $\alpha=.93$ to .95 ) has been reported for the FSI Interference Scale (Hann, Denniston, \& Baker, 2000; Hann et al., 1998), and scores were correlated with the POMS-F $(r=.78, p<.01)$ in a sample of patients with cancer (Hann et al., 2000).

\section{Profile of Mood States}

The POMS was initially developed to evaluate changes in mood with psychotherapy (McNair, Lorr, \& Doppleman, 2005), but investigators have also used the POMS to measure mood in patients with cancer (Hann et al., 1998; Hann et al., 2000; Meek et al., 2000; Schwartz et al., 2002; Yellen, Cella, Webster, Blendowski, \& Kaplan, 1997), in patients with heart failure (Evangelista et al., 2008; Mayou, Blackwood, Bryant, \& Garnham, 1991; 
Stephen, 2008), and in healthy adults (Belza, 1995; Hann et al., 1998; Lee, Hicks, \& NinoMurcia, 1991; Nyenhuis, Yamamoto, Luchetta, Terrien, \& Parmentier, 1999). In the present study, we report findings from the 7-item fatigue/inertia subscale (POMS-F, score range 028), 8-item vigor/activity subscale (score range 0-28), 15-item depression/dejection subscale (score range 0-60), 9-item anxiety/tension subscale (score range 0-36), and 12-item anger/ hostility subscale (score range 0-48). Higher scores on the POMS subscales reflect a greater agreement with the mood state during the past week. Adequate internal consistency reliability $(\alpha>.80)$ has been reported for the POMS subscales (Belza, 1995; Evangelista et al., 2008; McNair, Lorr, \& Droppleman, 2005). The POMS-F has been correlated with other fatigue measures, such as the Functional Assessment of Cancer Therapy fatigue subscale $(r$ $=-.74, p<.05)$, the revised Piper Fatigue Scale $(r=.75, p=.01$; Yellen et al., 1997), and the visual analogue Lee Fatigue Scale $(r=.78, p<.01$; Lee et al., 1991).

\section{Medical Outcomes Study Short Form 36 Health Survey}

The SF-36 is widely used in the cardiovascular literature to measure quality of life and physical and mental components of health (Colak et al., 2008; Dempster \& Donnelly, 2000; Dickens et al., 2006). The scales in the SF-36 have been recognized for internal consistency reliability and validity (McHorney, Ware, Lu, \& Sherbourne, 1994; Ware, Snow, Kosinski, $\&$ Gandek, 1993), and the SF-36 has been used as a criterion for establishing cut-off scores on other instruments (Donovan et al., 2008). There are eight scales in the SF-36, and they correlate with the SF-36 physical component composite score (Physical Functioning, RolePhysical, Bodily Pain Scales), the mental component composite score (Mental Health and Role-Emotional Scales), or both components (Vitality, General Health, and Social Functioning Scales). An advantage of using the SF-36 scales is that the calculated scores are standardized according to norms for the U.S. population. Scores on each scale range from 0 to 100 , with higher scores reflecting better functioning within the past month. In addition, norms by gender and age group from large sample sizes have been published for the SF-36 scales, making possible comparisons across populations (McHorney et al., 1994; Ware, 2000).

The 4-item SF-36 Vitality Scale has been used as a proxy measure for fatigue. Using a Likert-type scale, patients report their agreement with two positively scored items ("Did you feel full of life?" and "Did you have a lot of energy?") and two negatively scored items ("Did you feel worn out?" and "Did you feel tired?"). Like the other SF-36 scales, the vitality scores are standardized according to U.S. population norms, and scores range from 0 to 100 , with higher scores reflecting greater vitality in the past month. We also used the 10item Physical Functioning Scale and the 2-item Bodily Pain Scale from the SF-36 in this study.

\section{Analysis}

Data were analyzed using the Statistical Package for the Social Sciences (SPSS) version 15.0 (Chicago, Illinois). An alpha level of .05 was selected for statistical significance. Missing data were replaced with predicted values (if a subject answered at least $90 \%$ of the items in a scale). Differences between patients' demographic characteristics for Time 1 and Time 2 were compared using $\chi^{2}$ analyses. Internal consistency reliability (Cronbach's $\alpha$ ) was examined for all subscales in the analyses. For Hypotheses 1 and 2, Pearson productmoment correlation coefficients $(r)$ were calculated to examine the correlations between subscales. For Hypothesis 3, independent $t$ tests were used to compare patients' scores (Time 1) to published scores obtained from the literature (Hann et al., 1998; Nyenhuis et al., 1999; Ware, Kowinski, \& Dewey, 2000) for healthy adults. For Hypothesis 4, paired $t$ tests were used to compare patients' Time 1 and Time 2 scores. 


\section{Results}

\section{Sample Demographics}

Demographic and clinical characteristics of the sample are shown in Table 1. Most patients were male, non-Hispanic White, and married. The mean age was $60(S D=11)$ at Time 1 and $61(S D=10)$ at Time 2. More than half of the patients had completed a high school-level education. Many patients had risk factors for MI, such as hypertension or hyperlipidemia. Patients who returned the questionnaires at Time 2 were more likely to be non-Hispanic White and to have completed education beyond high school.

\section{Internal Consistency Reliability}

Internal consistency reliability is a critical quality of a good measure and indicates that the items in a scale or subscale are conceptually related to each other. A Cronbach's alpha coefficient $(\alpha)$ of at least .80 for established instruments reflects adequate internal consistency (Nunnally, 1978). Adequate internal consistency was noted for the FSI Interference Scale (Time 1: $\alpha=.89$; Time 2: $\alpha=.88$ ), POMS-F (Time 1: $\alpha=.89$; Time 2: $\alpha$ $=.91$ ), and SF-36 Vitality Scale (Time 1: $\alpha=.83$; Time 2: $\alpha=.85$ ). All of the other scales used in the analysis were internally consistent at Time 1 and Time 2, respectively: POMS Vigor subscale $(\alpha=.86, .87)$, POMS Depression subscale $(\alpha=.90, .89)$, POMS Anxiety subscale $(\alpha=.86, .84)$, POMS Anger subscale $(\alpha=.88, .90)$, SF-36 Physical Functioning Scale $(\alpha=.93, .87)$, and SF-36 Bodily Pain Scale $(\alpha=.85, .85)$.

\section{Hypothesis 1 (Convergent Validity)}

We expected to find evidence of convergent validity for the fatigue measures because the three instruments were designed to measure the same construct. Using criteria published by Cohen (1988) about the strength of correlations, we expected to find moderate or stronger positive correlations $(r>+.50)$ between the FSI Interference Scale and the POMS-F, and moderate or stronger inverse correlations $(r>-.50)$ between the SF-36 Vitality Scale and each of the other two fatigue measures. This hypothesis was supported (Table 2).

\section{Hypothesis 2 (Discriminant Validity-Correlation Matrix)}

We expected to find weak correlations $(r \leq .30)$ between fatigue and other mood states, but we did not find support for this hypothesis (Table 2). All three fatigue measures had correlations greater than .30 with the different mood states measured by the POMS (e.g., vigor, depressed mood, anxiety). Furthermore, the FSI Interference Scale scores were correlated ( $\geq .30)$ with both the SF-36 Physical Functioning Scale and Bodily Pain Scale scores. Scores on the POMS-F and SF-36 Vitality Scale, however, were weakly correlated with the physical functioning scores and were not correlated with bodily pain scores.

\section{Hypothesis 3 (Discriminant Validity-Healthy Group Comparison)}

We found support for the hypothesis that patients' fatigue scores at Time $1(n=116)$ were significantly greater than scores for healthy adults published in other studies. FSI Interference Scale scores for 94 healthy adults were obtained from Hann et al. (1998), and POMS-F scores were obtained for 432 healthy adults from Nyenhuis et al. (1999). Normative data from 1,046 healthy adults published by Ware et al. (2000) were used for comparisons of SF-36 Vitality Scale scores. On the FSI Interference Scale, patients with MI $(M=3.2, S D=2.3)$ reported significantly more fatigue than healthy adults $(M=1.3, S D=$ $1.4 ; t=4.6, p<.0001)$. Consistent with this finding, on the POMS-F patients with MI $(M=$ $12.3, S D=7.4)$ reported significantly more fatigue than healthy adults $(M=7.3, S D=5.7 ; t$ $=7.3, p<.0001)$. In addition, patients with MI reported significantly lower SF-36 Vitality 
scores $(M=45.9, S D=11.6)$ than healthy individuals $(M=58.4, S D=10.7 ; t=6.0, p<$. 0001).

\section{Hypothesis 4 (Construct Validity)}

We hypothesized that patients would report less fatigue after MI than before MI. This hypothesis was supported for only the POMS-F, on which Time 1 scores $(M=13.0, S D=$ 7.4) were significantly higher than Time 2 scores $(M=9.6, S D=5.9$; paired $t=3.2, p<$. 003). FSI Interference Scale scores did not differ significantly between Time $1(M=2.8, S D$ $=2.3)$ and Time $2(M=2.1, S D=1.7$; paired $t=1.7, p=.09)$. Similarly, SF-36 Vitality Scale scores did not differ significantly between Time $1(M=46.6, S D=12.0)$ and Time 2 $(M=47.9, S D=9.9 ;$ paired $t=-.69, p=.49)$.

\section{Discussion}

In this study of men and women with MI, we found that the FSI Interference Scale, POMSF, and SF-36 Vitality Scale were internally consistent measures of fatigue, and we found evidence of convergent validity for these instruments. We did not find very strong correlations among these fatigue measures, which indicates that they measure different aspects of fatigue. We examined relationships between the fatigue measures and other constructs to better understand how each of these instruments measures fatigue. The FSI Interference Scale was the only fatigue measure found to correlate with SF-36 Bodily Pain scores. The FSI Interference Scale includes items about the effect of fatigue on mood, the ability to concentrate, the ability to perform work, and enjoyment of life, and patients with pain may report higher scores on these items. Similarly, the correlation between fatigue and physical functioning (SF-36) was stronger for the FSI Interference Scale compared with the other two fatigue measures. This finding may be explained by items on the FSI Interference Scale about the degree to which fatigue affects one's general level of activity, the ability to bathe and dress, and the ability to perform work and housework. Patients who experienced poor physical functioning in the week before MI may be likely to endorse these items with high scores, as well as report higher limitations on the SF-36 Physical Functioning Scale for their ability to perform physical activities (e.g., running, lifting, and climbing stairs).

All three instruments measured the psychological aspects of fatigue. The relationship between fatigue and depressed mood was particularly strong, and anxiety was also correlated with fatigue, particularly for the POMS-F. Fatigue is a symptom of depression, and many patients with mood disorders experience both depression and anxiety. Therefore, instruments that measure depression, anxiety, and fatigue may not differentiate these moods and their symptoms completely (Bramley, Easton, Morley, \& Snaith, 1988). Similarly, feelings of anger may accompany mood disorders in some individuals, which explains the significant correlations between fatigue and anger found in this study.

Scores on the FSI Interference Scale, POMS-F, and SF-36 Vitality Scales discriminated between the more severe fatigue reported by patients with MI and the lower levels of fatigue documented in other studies of healthy adults. Considering the ability to differentiate between these groups, these instruments may be useful for clinicians to identify patients with cardiovascular risk factors who report clinically significant fatigue. Although a cut-off has not been identified for cardiac patients, a score greater than 3 on any FSI item indicates clinically significant fatigue in patients with cancer (Donovan et al., 2008). Cut-off scores are not used to interpret POMS-F or SF-36 scores, but normative data are available for different populations (McNair et al., 2005; Nyenhuis et al., 1999; Ware, 2000).

Using the POMS-F, we found a significant decrease in fatigue levels after MI. But this decline in fatigue was not supported on either the FSI Interference Scale or the SF-36 
Vitality Scale. In a post hoc power analysis (G-power, Version 3.0.10, Universitat Kiel, Germany), we found that the power of our comparisons (paired $t$ tests, $\alpha=.05$, two-tailed) for the FSI Interference Scale and SF-36 Vitality Scale were .38 and .11, respectively. Fiftyeight percent of the sample did not return their Time 2 questionnaires, and we did not have a large enough sample to detect differences between Time 1 and Time 2 scores on the FSI Interference Scale or on the SF-36 Vitality Scale. Further research is needed to test the responsiveness of these instruments to changes in fatigue after MI.

The strengths of this study include the administration of multiple instruments to measure fatigue and the comparison of fatigue before and after MI. Limitations include the significant attrition, the lack of a prospective control group, and the omission of other variables that influence fatigue (i.e., sleep). The loss of $60 \%$ of the sample may result in some bias, and it is possible that scores may differ between patients who did and who did not return their Time 2 questionnaires. For example, patients who chose not to complete the Time 2 measures may have been experiencing more fatigue and depression. In addition, by having a single follow-up time period, we did not measure the long-term course of fatigue after MI. It is not known to what extent the Time 2 fatigue scores reflected physiological recovery or pharmacological adjustments. We did not have access to patients' medical records at Time 2; therefore, any changes in medication and medical history reported at Time 2 were according to patients' self-report.

We found evidence of strong psychometric properties for the FSI Interference Scale, POMSF, and SF-36 in this study. Using the POMS-F, we measured a reduction in fatigue after MI, which suggests that this instrument may be more responsive to changes in fatigue compared to the other two instruments. All three instruments appear to have utility in clinical practice settings for measuring a patient's fatigue in comparison to either a cut-off score or to normative data. Although not addressed in this study, other measures are important in future fatigue research, such as sleep quality and physiological variables (i.e., medications, anemia). Future research should focus on clarifying the relationships among fatigue, mood states, physical limitations, pain, and sleep quality, as well as examining trends in the course of fatigue following MI.

\section{Acknowledgments}

The authors acknowledge Dr. Maureen M. Friedman for her comments on this manuscript and thank Kevin Grandfield for editorial assistance.

\section{Funding}

The authors disclosed receipt of the following financial support for the research and/or authorship of this article: This project was supported by the National Institute of Nursing Research: Grant F31NR010810, National Research Service Award, and P30NR009014, Center for Reducing Risks in Vulnerable Populations (CRRVP). The content is solely the responsibility of the authors and does not necessarily represent the official views of the National Institute of Nursing Research or the National Institutes of Health.

\section{References}

Aaronson LS, Teel CS, Cassmeyer V, Neuberger GB, Pallikkathayil L, Pierce J, Wingate A. Defining and measuring fatigue. Image-The Journal of Nursing Scholarship 1999;31:45-50. [PubMed: 10081212]

Alsén P, Brink E, Persson LO. Living with incomprehensible fatigue after recent myocardial infarction. Journal of Advanced Nursing 2008;64:459-468. [PubMed: 19146515]

Appels A, Mulder P. Excess fatigue as a precursor of myocardial infarction. European Heart Journal 1988;9:758-764. [PubMed: 3169045] 
Belza BL. Comparison of self-reported fatigue in rheumatoid arthritis and controls. Journal of Rheumatology 1995;22:639-643. [PubMed: 7791155]

Bramley PN, Easton AM, Morley S, Snaith RP. The differentiation of anxiety and depression by rating scales. Acta Psychiatrica Scandinavica 1988;77:133-138. [PubMed: 3364199]

Cohen, J. Statistical power analysis for the behavioral sciences. 2. Hillsdale, NJ: Lawrence Erlbaum; 1988.

Colak Z, Segotic I, Uzun S, Mazar M, Ivancan V, Majeric-Kogler V. Health related quality of life following cardiac surgery-Correlation with EuroSCORE. European Journal of Cardiothoracic Surgery 2008;33:72-76. [PubMed: 17977006]

Dempster M, Donnelly M. Measuring the health related quality of life of people with ischaemic heart disease. Heart 2000;83:641-644. [PubMed: 10814620]

DeVon H, Ryan C, Zerwic J. Is the medical record an accurate reflection of patients' symptoms during acute myocardial infarction? Western Journal of Nursing Research 2004;26:547-560. [PubMed: 15359057]

Dickens CM, McGowan L, Percival C, Tomenson B, Cotter L, Heagerty A, Creed FH. Contribution of depression and anxiety to impaired health-related quality of life following first myocardial infarction. British Journal of Psychiatry 2006;189:367-372. [PubMed: 17012661]

Donovan KA, Jacobsen PB, Small BJ, Munster PN, Andrykowski MA. Identifying clinically meaningful fatigue with the Fatigue Symptom Inventory. Journal of Pain and Symptom Management 2008;36:480-487. [PubMed: 18495413]

Evangelista LS, Moser DK, Westlake C, Pike N, Ter-Galstanyan A, Dracup K. Correlates of fatigue in patients with heart failure. Progress in Cardiovascular Nursing 2008;23:12-17. [PubMed: 18326992]

Friedman, MM.; Stephens, SA. Fatigue. In: Moser, DK.; Riegel, B., editors. Cardiac nursing: A companion to Braunwald's heart disease. St. Louis, MO: Saunders; 2008. p. 782-788.

Hann DM, Denniston MM, Baker F. Measurement of fatigue in cancer patients: Further validation of the Fatigue Symptom Inventory. Quality of Life Research 2000;9:847-854. [PubMed: 11297027]

Hann DM, Jacobsen PB, Azzarello LM, Martin SC, Curran SL, Fields KK, Lyman G. Measurement of fatigue in cancer patients: Development and validation of the Fatigue Symptom Inventory. Quality of Life Research 1998;7:301-310. [PubMed: 9610214]

Irvine J, Basinski A, Baker B, Jandciu S, Paquette M, Cairns J, Dorian P. Depression and risk of sudden cardiac death after acute myocardial infarction: Testing for the confounding effects of fatigue. Psychosomatic Medicine 1999;61:729-737. [PubMed: 10593621]

Johnson JA, King L. Influence of expectations about symptoms on delay in seeking treatment during a myocardial infarction. American Journal of Critical Care 1995;4:29-35. [PubMed: 7894552]

Lee KA, Hicks G, Nino-Murcia G. Validity and reliability of a scale to assess fatigue. Psychiatry Research 1991;36:291-298. [PubMed: 2062970]

Lloyd-Jones D, Adams R, Carnethon M, De Simone G, Ferguson TB, Flegal K, Hong Y. Heart disease and stroke statistics 2009 update: A report from the American Heart Association Statistics Committee and Stroke Statistics Subcommittee. Circulation 2009;119:480-486. [PubMed: 19171871]

Mayou R, Blackwood R, Bryant B, Garnham J. Cardiac failure: Symptoms and functional status. Journal of Psychosomatic Research 1991;35:399-407. [PubMed: 1920171]

McHorney CA, Ware JE Jr, Lu JF, Sherbourne CD. The MOS 36-item short-form health survey (SF-36): III. Tests of data quality, scaling assumptions, and reliability across diverse patient groups. Medical Care 1994;32:40-66. [PubMed: 8277801]

McNair, DM.; Lorr, M.; Droppleman, LF. Profile of mood states: A manual. San Diego, CA: Educational and Industrial Testing Services; 2005.

McSweeney JC, Cody M, O’Sullivan P, Elberson K, Moser DK, Garvin BJ. Women's early warning symptoms of acute myocardial infarction. Circulation 2003;108:2619-2623. [PubMed: 14597589]

McSweeney JC, Crane PB. Challenging the rules: Women's prodromal and acute symptoms of myocardial infarction. Research in Nursing \& Health 2000;23:135-146. [PubMed: 10782872] 
Meek PM, Nail LM, Barsevick A, Schwartz AL, Stephen S, Whitmer K, Walker BL. Psychometric testing of fatigue instruments for use with cancer patients. Nursing Research 2000;49:181-190. [PubMed: 10929689]

Meeske KA, Siegel SE, Globe DR, Mack WJ, Bernstein L. Prevalence and correlates of fatigue in long-term survivors of childhood leukemia. Journal of Clinical Oncology 2005;23:5501-5510. [PubMed: 16110010]

Nixon PG, Bethell HJ. Preinfarction ill health. American Journal of Cardiology 1974;33:446-449. [PubMed: 4812565]

Nunnally, JC. Psychometric theory. 2. New York, NY: McGraw-Hill; 1978.

Nyenhuis DL, Yamamoto C, Luchetta T, Terrien A, Parmentier A. Adult and geriatric normative data and validation of the profile of mood states. Journal of Clinical Psychology 1999;55:79-86. [PubMed: 10100834]

Piper BF, Lindsey AM, Dodd MJ. Fatigue mechanisms in cancer patients: Developing nursing theory. Oncology Nursing Forum 1987;14(6):17-23. [PubMed: 3320981]

Ream E, Richardson A. Fatigue: A concept analysis. International Journal of Nursing Studies 1996;33:519-529. [PubMed: 8886902]

Ryan CJ, DeVon HA, Horne R, King KB, Milner K, Moser DK, Zerwic JJ. Symptom clusters in acute myocardial infarction: A secondary data analysis. Nursing Research 2007;56(2):72-81. [PubMed: 17356437]

Ryan CJ, DeVon HA, Zerwic JJ. Typical and atypical symptoms: Diagnosing acute coronary syndromes accurately. American Journal of Nursing 2005;105(2):34-36. [PubMed: 15674053]

Schuitemaker GE, Dinant GJ, Appels A. Assessment of vital exhaustion and identification of subjects at increased risk of myocardial infarction in general practice. Psychosomatics 2004;45:414-418. [PubMed: 15345786]

Schwartz AL, Meek PM, Nail LM, Fargo J, Lundquist M, Donofrio M, Mateo M. Measurement of fatigue. Determining minimally important clinical differences. Journal of Clinical Epidemiology 2002;55:239-244. [PubMed: 11864794]

Shin JY, Martin R, Howren MB. Influence of assessment methods on reports of gender differences in AMI symptoms. Western Journal of Nursing Research 2009;31:553-568. [PubMed: 19363164]

Stephen SA. Fatigue in older adults with stable heart failure. Heart \& Lung 2008;37:122-131. [PubMed: 18371505]

Varvaro FF, Sereika SM, Zullo TG, Robertson RJ. Fatigue in women with myocardial infarction. Health Care Women International 1996;17:593-602.

Ware JE. SF-36 health survey update. Spine 2000;25:3130-3139. [PubMed: 11124729]

Ware, JE.; Kowinski, M.; Dewey, JE. How to score version 2 of the SF-36 health survey. Lincoln, RI: QualityMetric; 2000.

Ware, JE.; Snow, KK.; Kosinski, M.; Gandek, B. SF-36 ${ }^{\circledR}$ Health Survey Manual and Interpretation Guide. Boston, MA: New England Medical Center, The Health Institute; 1993.

Whitehead L. The measurement of fatigue in chronic illness: A systematic review of unidimensional and multidimensional fatigue measures. Journal of Pain and Symptom Management 2009;37:107128. [PubMed: 19111779]

Yellen SB, Cella DF, Webster K, Blendowski C, Kaplan E. Measuring fatigue and other anemiarelated symptoms with the functional assessment of cancer therapy (FACT) measurement system. Journal of Pain and Symptom Management 1997;13:63-74. [PubMed: 9095563] 
Table 1

Sample Demographics and Clinical Characteristics

\begin{tabular}{|c|c|c|c|}
\hline & Time $1(n=116), n(\%)$ & Time $2(n=49), n(\%)$ & $\chi^{2}$ Statistic \\
\hline Gender & & & 0.64 \\
\hline Male & $88(76)$ & $39(80)$ & \\
\hline Female & $28(24)$ & $10(20)$ & \\
\hline Race & & & $13.6^{* *}$ \\
\hline White, non-Hispanic & $86(74)$ & $44(90)$ & \\
\hline African American & $23(20)$ & $2(4)$ & \\
\hline Hispanic/Latino & $4(3)$ & $2(4)$ & \\
\hline Other & $3(3)$ & $1(2)$ & \\
\hline Marital status & & & 3.7 \\
\hline Married/long-term relationship & $82(71)$ & $35(72)$ & \\
\hline Divorced/separated/widowed & $25(21)$ & $10(20)$ & \\
\hline Single & $9(8)$ & $4(8)$ & \\
\hline Education & & & $15.1^{*}$ \\
\hline$<$ High school & $55(47)$ & $17(34)$ & \\
\hline High school graduate & $6(5)$ & $1(2)$ & \\
\hline College (2- or 4-year) & $40(34)$ & $17(35)$ & \\
\hline Graduate degree & $18(15)$ & $14(29)$ & \\
\hline Employment & & & $11.9^{* *}$ \\
\hline Employed (full- or part-time) & $51(44)$ & $17(35)$ & \\
\hline Retired & $8(7)$ & $0(0)$ & \\
\hline Unemployed/disabled & $57(49)$ & $32(65)$ & \\
\hline \multicolumn{4}{|l|}{ Medical history } \\
\hline Hypertension & $56(48)$ & $22(45)$ & 0.15 \\
\hline Hyperlipidemia & $51(44)$ & $21(43)$ & 0.47 \\
\hline Stroke & $6(5)$ & $1(2)$ & 0.15 \\
\hline Pulmonary disease & $10(9)$ & $6(12)$ & 1.12 \\
\hline Current smoker & $46(40)$ & $22(45)$ & 1.11 \\
\hline Diabetes mellitus & $37(32)$ & $16(32)$ & 0 \\
\hline Peripheral vascular disease & $9(8)$ & $5(10)$ & 0.64 \\
\hline Medication: beta-blocker use ${ }^{a}$ & $42(36)$ & $30(61)$ & $3.76^{*}$ \\
\hline \multicolumn{4}{|l|}{$p<.05}$. \\
\hline$* * * 0.01$ & & & \\
\hline
\end{tabular}

West J Nurs Res. Author manuscript; available in PMC 2010 December 8. 


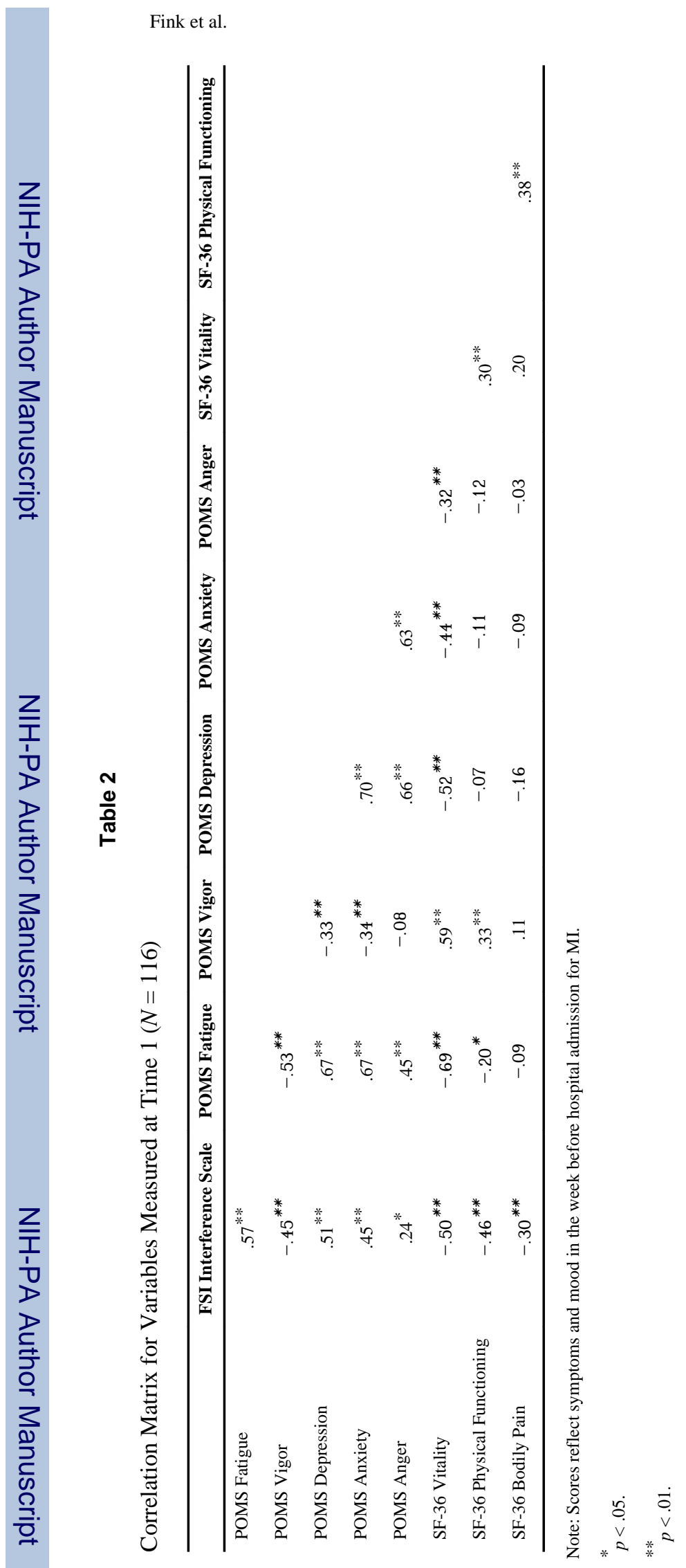

West J Nurs Res. Author manuscript; available in PMC 2010 December 8. 